\title{
Chapter 5 \\ What is Mathematical Proficiency and How Can It Be Assessed?
}

\author{
ALAN H. SCHOENFELD
}

To establish a common point of departure with Jim Milgram's chapter, this chapter is framed around the two basic questions with which his chapter began:

- What does it mean for a student to be proficient in mathematics? (What should students be learning?)

- How can we measure proficiency in mathematics? (How can we tell if we are succeeding?)

My main emphasis is on the first question, because much of the rest of this volume addresses the second.

In the introduction to this volume and in the first chapter, I pointed to the fact that the "cognitive revolution" (see [Gardner 1985], for instance) produced a significant reconceptualization of what it means to understand subject matter in different domains (see also [NRC 2000]). There was a fundamental shift from an exclusive emphasis on knowledge - what does the student know? - to a focus on what students know and can do with their knowledge. The idea was not that knowledge is unimportant. Clearly, the more one knows, the greater the potential for that knowledge to be used. Rather, the idea was that having the knowledge was not enough; being able to use it in the appropriate circumstances is an essential component of proficiency.

Some examples outside of mathematics serve to make the point. Many years ago foreign language instruction focused largely on grammar, vocabulary, and literacy. Students of French, German, or Spanish learned to read literature in those languages - but when they visited France, Germany, or Spain, they found themselves unable to communicate effectively in the languages they had studied. Similarly, years of instruction in English classes that focused on grammar instruction resulted in students who could analyze sentence structure but who were not necessarily skilled at expressing themselves effectively in writing. Over the 
past few decades, English and foreign language instruction have focused increasingly on communication skills - on mastering the basics, of course (e.g., conjugating verbs, acquiring a solid vocabulary, mastering grammar) and learning the additional skills that enable them to use what they have learned.

A similar evolution took place in mathematics. The knowledge base remains important; it goes without saying that anyone who lacks a solid grasp of facts, procedures, definitions, and concepts is significantly handicapped in mathematics. But there is much more to mathematical proficiency than being able to reproduce standard content on demand. A mathematician's job consists of at least one of: extending known results; finding new results; and applying known mathematical results in new contexts. The problems mathematicians work on, in academia or in industry, are not the kind of exercises that get solved in a few minutes or hours; they are problems that may take days, weeks, months, or years to solve. Thus, in addition to possessing a substantial amount of specialized knowledge, mathematicians possess other things as well. Good problem solvers are flexible and resourceful. The have many ways to think about problems alternative approaches if they get stuck, ways of making progress when they hit roadblocks, of being efficient with (and making use of) what they know. They also have a certain kind of mathematical disposition - a willingness to pit themselves against difficult mathematical challenges under the assumption that they will be able to make progress on them, and the tenacity to keep at the task when others have given up. As will be seen below, all of these are aspects of mathematical proficiency; all of them can be learned (or not) in school; all of them can help explain why some attempts at problem solving are successful and some not.

\section{Proficiency, Part A: Knowledge Base}

There is a long history of attempts to prescribe the mathematical content that students should know. Many of those efforts have involved having groups of scholars working together for a number of years. It would be foolish for me to try to supplant their work, especially given the small amount of space available. Hence I will defer to the judgments made in volumes such as the National Council of Teachers of Mathematics' two major standards documents [NCTM 1989; 2000], especially the latter, Principles and Standards for School Mathematics; and the National Research Council's [NRC 2001] volume Adding It $U p$. (Note: a summary of the dimensions of mathematical proficiency found in those volumes was given in Chapter 1 of this volume, "Issues and Tensions in the Assessment of Mathematical Proficiency.")

Instead, I will discuss different interpretations of what it means to know that content. A major source of controversy over the past decade has involved not 
only the level of procedural skills expected of students, but also what is meant by "understanding." For example, what does it mean for an elementary school student to understand base-ten subtraction?

For some people - notably, those who wrote the current California mathematics standards, understanding a concept means being able to compute the answers to exercises that employ that concept. For example, here are the California mathematics standards related to arithmetic in grade 3 [CSBE 1997]:

2.0 Students calculate and solve problems involving addition, subtraction, multiplication, and division:

2.1 Find the sum or difference of two whole numbers between 0 and 10,000.

2.2 Memorize to automaticity the multiplication table for numbers between 1 and 10.

2.3 Use the inverse relationship of multiplication and division to compute and check results.

2.4 Solve simple problems involving multiplication of multidigit numbers by one-digit numbers $(3,671 \times 3=$

2.5 Solve division problems in which a multidigit number is evenly divided by a one-digit number $(135 \div 5=$

2.6 Understand the special properties of 0 and 1 in multiplication and division.

2.7 Determine the unit cost when given the total cost and number of units.

2.8 Solve problems that require two or more of the skills mentioned above.

and the California Grade 5 number sense standards:

2.0 Students perform calculations and solve problems involving addition, subtraction, and simple multiplication and division of fractions and decimals:

2.1 Add, subtract, multiply, and divide with decimals; add with negative integers; subtract positive integers from negative integers; and verify the reasonableness of the results.

2.2 Demonstrate proficiency with division, including division with positive decimals and long division with multidigit divisors.

2.3 Solve simple problems, including ones arising in concrete situations, involving the addition and subtraction of fractions and mixed numbers (like and unlike denominators of 20 or less), and express answers in the simplest form.

2.4 Understand the concept of multiplication and division of fractions.

2.5 Compute and perform simple multiplication and division of fractions and apply these procedures to solving problems. 
Although the term "problem solving" is used in these standards, it refers to computational proficiency: For example, in the third grade standard 2.4, we are told that students will be able to "solve" the "problem" $(3,671 \times 3=$

This approach stands in stark contrast to the one taken in the National Council of Teachers of Mathematics volume Principles and Standards for School Mathematics [NCTM 2000]. Consider, for example, the language used in describing the Number and Operations Standard for grades 3-5, from p. 148:

Instructional programs from prekindergarten through grade 12 should enable all students to:

Understand numbers, ways of representing numbers, relationships among numbers, and number systems.

In grades 3-5 all students should

- understand the place-value structure of the base-ten number system and be able to represent and compare whole numbers and decimals;

- recognize equivalent representations for the same number and generate them by decomposing and composing numbers;

- develop understanding of fractions as parts of unit wholes, as parts of a collection, as locations on number lines, and as divisions of whole numbers;

- use models, benchmarks, and equivalent forms to judge the size of fractions;

- recognize and generate equivalent forms of commonly used fractions, decimals, and percents;

- explore numbers less than 0 by extending the number line and through familiar applications;

- describe classes of numbers according to characteristics such as the nature of their factors.

Understand meanings of operations and how they relate to one another

(detail omitted)

Compute fluently and make reasonable estimates

(detail omitted)

The differences in terminology, meaning, and intended competencies are clear, as is the exemplification in Principles and Standards. Now the question is, does such a difference in setting standards make a difference? And does it make a difference in assessment?

The simple answer is that it can make a great deal of difference. For example, consider the following statistics from [Ridgway et al. 2000]. 
In 2000, the Silicon Valley Mathematics Assessment Collaborative gave two tests to a total of 16,420 third, fifth, and seventh graders. One was the SAT9, a skills-oriented test consistent with the California mathematics standards. The other was the Balanced Assessment test, a much broader test (including questions that focus on skills, concepts and problem solving) that is aligned with NCTM's (1989) Curriculum and Evaluation Standards for School Mathematics, the precursor to Principles and Standards. The simplest analysis assigns each student a score of "proficient" or "not proficient" on each examination. Needless to say, student scores on any two mathematics assessments are likely to be highly correlated — but, the differences between student scores on the SAT-9 and Balanced Assessment tests are very informative. Consider Table 1.

\begin{tabular}{lcc}
\hline \multirow{2}{*}{ Balanced } & \multicolumn{2}{c}{ SAT-9 } \\
\cline { 2 - 3 } Assessment & Not proficient & Proficient \\
\hline Not proficient & $29 \%$ & $22 \%$ \\
Proficient & $4 \%$ & $45 \%$ \\
\hline
\end{tabular}

Table 1. Aggregated scores for 16,420 Students on the SAT-9 and Balanced Assessment tests (grades 3, 5, and 7). From [Ridgway et al. 2000].

As expected, $74 \%$ of the students at grades 3, 5, and 7 were given the same "proficient" or "not proficient" ratings on the two tests. But, compare the second row of data to the second column. More than $90 \%$ of the students who were declared proficient on the Balanced Assessment test were declared proficient on the SAT-9 - that is, doing well on the Balanced Assessment tests is a reasonably good guarantee of doing well on the SAT-9. The converse is not true: approximately one third of the students declared proficient on the SAT-9 exam were declared to be not proficient on the Balanced Assessment test.

This is critically important, and entirely consistent with a small but growing body of literature comparing "reform" and "traditional" curricula in mathematics. (See, for example, [Senk and Thompson 2003], which examines the performance of students who studied curricula that had been developed with support from the National Science Foundation with more traditional, skills-oriented curricula.) In brief, the findings in that literature are as follows. Students who experience skills-focused instruction tend to master the relevant skills, but do not do well on tests of problem solving and conceptual understanding. Students who study more broad-based curricula tend to do reasonably well on tests of skills (that is, their performance on skills-oriented tests is not statistically different from the performance of students in skills-oriented courses), and they do 
much better than those students on assessments of conceptual understanding and problem solving.

In short, one's concept of what counts as mathematics matters a great dealand, what you assess counts a great deal. First, students are not likely to learn what they are not taught. Hence teaching a narrow curriculum has consequences. Second, one only finds out about what students don't know if one assesses for that knowledge. Thus, for example, the SAT-9 does not reveal the problem with a narrow curriculum: $22 \%$ of the total population is declared proficient although a more broad-based test calls that proficiency into question.

In what follows I shall briefly delineate additional aspects of mathematical proficiency.

\section{Proficiency, Part B: Strategies}

One of the strands of mathematical proficiency described in Adding It $U p$ is "strategic competence - ability to formulate, represent, and solve mathematical problems" [NRC 2001, p. 5]. It goes without saying that "knowing" mathematics, in the sense of being able to produce facts and definitions, and execute procedures on command, is not enough. Students should be able to use the mathematical knowledge they have.

The starting place for any discussion of problem solving strategies is the work of George Pólya. In 1945, with the pioneering first edition of How to Solve It, Pólya opened up the study of problem solving strategies. The core of the book was devoted to a "short dictionary of heuristic." To quote from Pólya, "The aim of heuristic is to study the methods and rules of discovery and invention. The present book is an attempt to revive heuristic in a modern and modest form" [Pólya 1945, pp. 112-113]. "Modern Heuristic endeavors to understand the process of solving problems, especially the mental operations typically useful in this process" [Pólya 1945, pp. 129-130]. In How to Solve It, Pólya described powerful problem solving strategies such as making use of analogy, making generalizations, re-stating or re-formulating a problem, exploiting the solution of related problems, exploiting symmetry, and working backwards. Polya's subsequent volumes, Mathematics and Plausible Reasoning [Pólya 1954] and Mathematical Discovery [Pólya 1981], elaborated substantially on the ideas in How to Solve It, showing how one could marshal one's mathematical knowledge in the service of solving problems.

To cut a long story short (see [Schoenfeld 1985; 1992] for detail), the heuristic strategies Pólya describes are more complex than they appear. Consider, for example, a strategy such as "if you cannot solve the proposed problem ... could you imagine a more accessible related problem?" [Pólya 1945, p. 114]. The idea is that although the problem you are trying to solve may be too difficult for 
now, you might be able to solve a simpler version of it. You might then use the result, or the idea that led to the solution of the simpler problem, to solve the original problem.

At this level of generality, the strategy sounds straightforward - but the devil is in the details. For example, Pólya [1945, p. 23] discusses the solution of this problem:

Using straightedge and compass, and following the traditional rules for geometric constructions, inscribe a square in a given triangle. Two vertices of the square should be on the base of the triangle, the other two vertices of the square on the other two sides of the triangle, one on each.

That is, you are given a triangle such as in the left diagram; you wish to produce a square such as seen on the right, using only straightedge and compass.

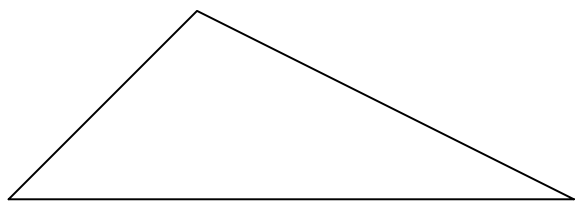

The given triangle

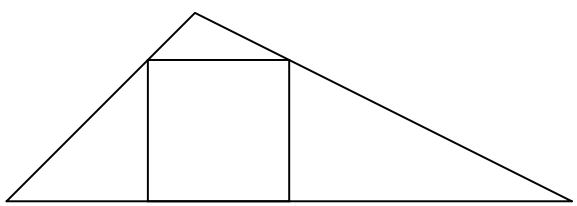

The desired construction

In an idealized discussion, Pólya shows how the right kind of questioning can lead a student to consider an easier related problem (demanding only that three of the corners of the desired square lie on the given triangle), noting that there are infinitely many squares that meet this condition, and that the locus of the fourth vertices of such squares can be used to find the one such square that has its fourth (and hence all four) vertices on the sides of the triangle. The discussion is logical and straightforward - and, once one sees the solution, it is wonderfully elegant. But the question is, what will non-ideal students do?

I have told undergraduates that the problem can be solved by exploiting the solution to an easier related problem, and asked them what easier related problem they might want to try to solve. Typically, they will suggest inscribing the square in a "special" triangle (such as an equilateral or isosceles triangle) or inscribing the square in a circle. Unfortunately, both of these approaches lead to dead ends. The former problem is no easier to solve than the original; the latter can be solved (it is a standard construction) but I know of no way to exploit it to solve the given problem. With further prodding, students will suggest inscribing a rectangle in the given triangle. They recognize that there are infinitely many rectangles that can be inscribed, and that one of them must be a square - but this is an existence proof, and it does not generate a construction. Then, students may suggest either (a) requiring only that three vertices of the square lie on the 
sides of the triangle, or (b) trying to circumscribe a square with a triangle similar to the given triangle. Each of these approaches does yield a solution, but not without some work.

In short, to use the strategy Pólya describes, the problem solver needs to

a. think to use the strategy,

b. generate a relevant and appropriate easier related problem,

c. solve the related problem, and

d. figure out how to exploit the solution or method to solve the original problem.

All of these can be nontrivial.

The evidence, however, is that accomplished mathematicians use such strategies (see not only Pólya's books but [DeFranco 1991]) and that high school and college students can learn to master such strategies; see, for example, [Lester 1994; Schoenfeld 1985; 1992].

\section{Proficiency, Part C: Metacognition (Using What You Know Effectively)}

Picture someone stepping into a bog, and beginning to sink in - then taking a second step forward and then a third, rather than turning back. By the time the person realizes that he or she is in quicksand, all is lost. One has to wonder, why didn't that person take stock before it was too late?

Now consider the following time-line graph (Figure 1) of two students working a problem.

In the specific problem session represented here (see [Schoenfeld 1985] for detail), the students read the problem statement and hastily made a decision about what to do next. Despite some clear evidence that this approach was not productive for them, they persevered at it until they ran out of time. When they did, I asked them how the approach they had taken - they had chosen to calculate a particular area - was going to help them. They were unable to say.

As it happens I knew these students well, and knew that each of them had enough mathematical knowledge to solve the given problem (which was similar to a problem on a final examination the students had taken just a week or two earlier). The point is that there is just so much that a student can be doing at any one time. Because the students were focused on doing a particular computation, and they had never stopped to consider how wise it was to invest their time in doing so, they never reconsidered - and thus never got to use the knowledge they had.

Reflecting on progress while engaged in problem solving, and acting accordingly ("monitoring and self-regulation") is one aspect of what is known as metacognition - broadly, taking one's thinking as an object of inquiry. As the 
Activity

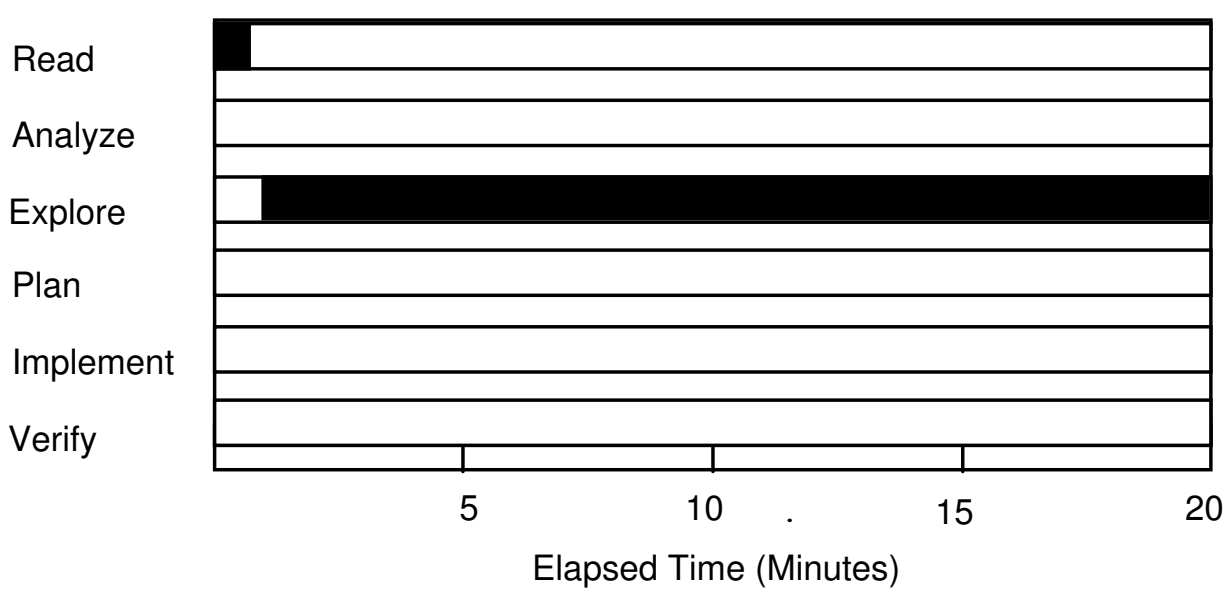

Figure 1. A time-line representation of a problem solving attempt. Reprinted from [Schoenfeld 1992], with permission.

graph above indicates, failing to do so can guarantee failure at problem solving: if one is fully occupied doing things that do not help to solve the problem, one may never get to use the "right" knowledge in the right ways.

Although I have told this story as an anecdote, there are lots of data to back it up. Over more than 25 years, more than half of the hundreds of problem sessions that my research assistants and I have videotaped have been of the type represented in Figure 1. This kind of finding has been widely replicated; for a general discussion see [Lester 1994] or [Schoenfeld 1987].

As was the case with strategies, the story here is that (a) effective problem solvers behave differently; and (b) students can learn to be much more efficient at monitoring and self-regulation, and become more successful problem solvers thereby.

Figure 2 shows the time-line graph of a mathematician working a two-part problem in a content area he had not studied for years. Each of the triangles in the figure represents a time that the mathematician assessed the state of his solution attempt and then acted on the basis of that assessment (sometimes deciding to change direction, sometimes deciding to stay the course - but always with decent reason). There is no question that he solved the problem because of his efficiency. He did not choose the right approaches at first, but, by virtue of not spending too much time on unproductive approaches, managed to find productive ones.

Figure 3 shows the time-line graph of a pair of students working a problem after having taken my problem solving course. During the course, I focused 
$\underline{\text { Activity }}$

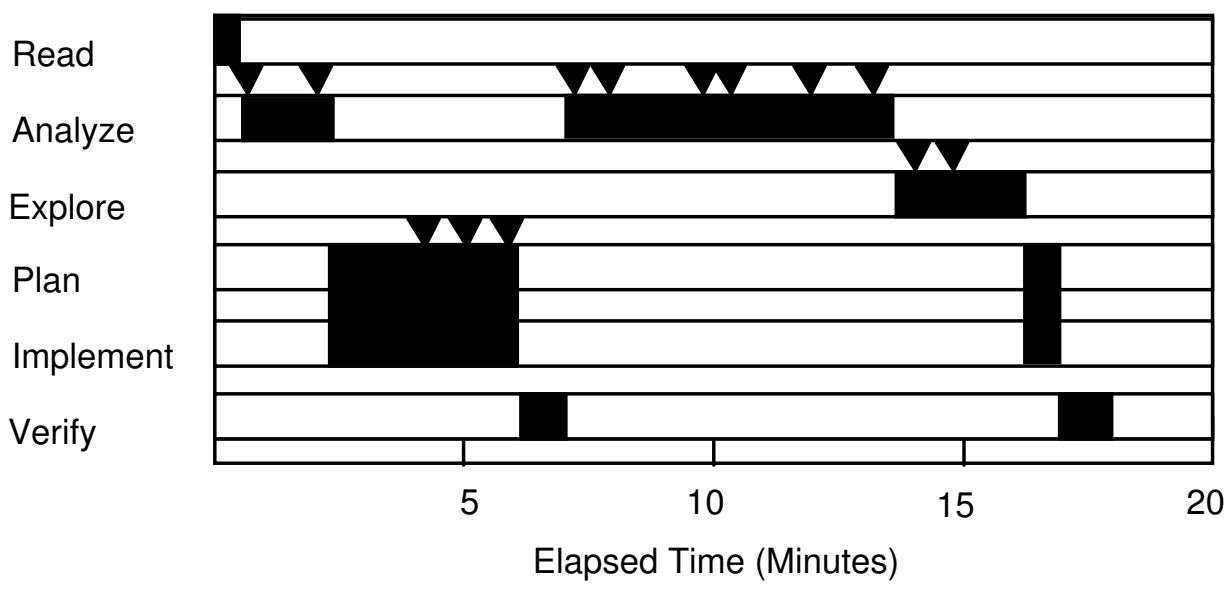

Figure 2. A time-line representation of a mathematician's problem solving attempt. Reprinted from [Schoenfeld 1992], with permission.

a great deal on issues of metacognition, acting as a "coach" while groups of students worked problems. (That is, I would regularly intervene to ask students if they could justify the solution paths they had chosen. After a while, the students began to discuss the rationales for their problem solving choices as they worked the problems.)

As Figure 3 indicates, the students hardly became "ideal" problem solvers. In the particular solution represented in Figure 3, the students jumped into a solution with little consideration after reading the problem. However, they reconsidered about four minutes into the solution, and chose a plausible solution direction. As it happens, that direction turned out not to be fruitful; about eight minutes later they took stock, changed directions, and went on to solve the problem. What made them effective in this case was not simply that they had the knowledge that enabled them to solve the problem. It is the fact that they gave themselves the opportunity to use that knowledge, by truncating attempts that turned out not to be profitable.

\section{Proficiency, Part D: Beliefs and Dispositions}

I begin this section, as above, with a description of one of the strands of mathematical proficiency described in Adding It Up: "productive disposition" an "habitual inclination to see mathematics as sensible, useful and worthwhile, coupled with a belief in diligence and one's own efficacy" [NRC 2001, p. 5].

Readers who know the research literature will find the idea that "beliefs and dispositions" are aspects of mathematical proficiency is familiar-but those 
Activity

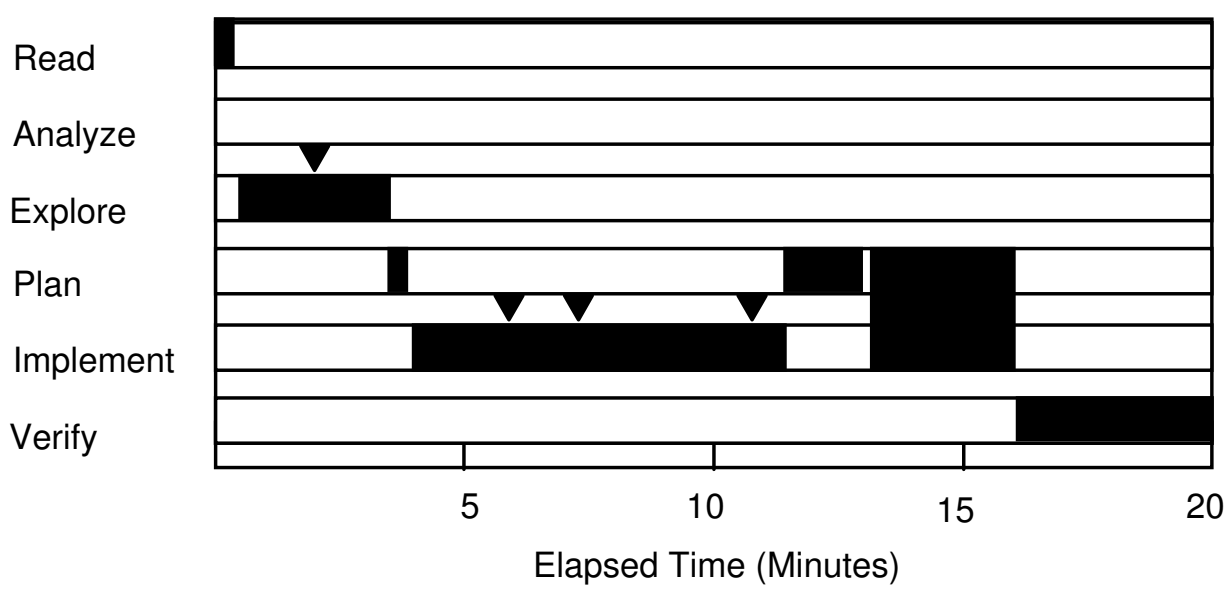

Figure 3. A time-line representation of two students' problem solving attempt, following the completion of a course on problem solving. Reprinted from [Schoenfeld 1992], with permission.

who do not are likely to find it rather strange. After all, what do beliefs have to do with doing mathematics? The simple answer is, "a great deal." Also as above, I shall indicate that this category of behavior matters (a) for students, and (b) for professional mathematicians.

What follows is a straightforward arithmetic problem taken from the 1983 National Assessment of Educational Progress, or NAEP [Carpenter et al. 1983]:

An army bus holds 36 soldiers. If 1128 soldiers are being bussed to their training site, how many buses are needed?

The solution is simple. If you divide 1128 by 36 , you get a quotient of 31 and a remainder of 12 . Hence you need 32 buses, under the (tacit) assumptions that each bus will be filled to capacity if possible and that no buses will be allowed to carry more 36 soldiers.

NAEP is a nationwide survey of U.S. students' mathematical performance, with a carefully undertaken sampling structure. Some 45,000 students worked this problem. Here is how the responses were distributed:

$29 \%$ gave the answer " 31 remainder 12 "

$18 \%$ gave the answer " 31 "

$23 \%$ gave the correct answer, "32"

$30 \%$ did the computation incorrectly.

A full $70 \%$ of the students did the computation correctly, but only $23 \%$ of the students rounded up correctly. How could this be? How could it be possible 
that $29 \%$ of the students answered that the number of buses needed involves a remainder? Imagine asking these same students to call a bus company to arrange for buses to take their school on an outing. Would any of them mention remainders?

The brief explanation for this astounding behavior (see [Schoenfeld 1985; 1992] for more detail) is that these students had learned their counterproductive behavior in their mathematics classes. In the late 1970s and early 1980s, there was an increased emphasis on "problem solving" in mathematics classrooms in the U.S. The reality (and the reason for the quotation marks) is that the focus was almost entirely superficial: instead of being given pages of rote computational problems such as

$$
7-4=
$$

students were given pages of comparably rote problems of the type

John had 7 apples. He gave 4 apples to Mary.

How many apples does he have left?

The students soon figured out that the word problems were "cover stories" that had little or nothing to do with the real world. The most efficient way to solve the problems was to read the text, ignoring the "real world" context. The students learned to pick out the numbers, identify the operation to perform on them, do the computation, and write the answer. That is, a quick scan of the word problem produces the following: "7 and 4 are the numbers. Subtract, and write the answer down." This procedure got students the right answer, almost all the time. It became a habit.

Now apply it to the NAEP busing problem. A quick scan of the problem statement produces " 1128 and 36 are the numbers. Divide, and write the answer down." If you do - and $29 \%$ of the students taking the exam did - you write that the answer is " 31 remainder 12."

In short, if you believe that mathematics is not supposed to make sense, and that working mathematics problems involves rather meaningless operations on symbols, you will produce nonsensical responses such as these. Hence beliefs are important - and, students pick up their beliefs about the nature of mathematics from their experiences in the mathematics classroom. Other typical student beliefs, documented over many years (see [Lampert 1990; Schoenfeld 1992]), include:

- Mathematics problems have one and only one right answer.

- There is only one correct way to solve any mathematics problem - usually the rule the teacher has most recently demonstrated to the class. 
- Ordinary students cannot expect to understand mathematics; they expect simply to memorize it, and apply what they have learned mechanically and without understanding.

- Mathematics is a solitary activity, done by individuals in isolation.

- Students who have understood the mathematics they have studied will be able to solve any assigned problem in five minutes or less.

- The mathematics learned in school has little or nothing to do with the real world.

- Formal proof is irrelevant to processes of discovery or invention.

(Reprinted with permission from [Schoenfeld 1992, p. 359])

One might think that professional mathematicians, especially those who have earned the Ph.D. in mathematics, would have productive beliefs about themselves and their engagement with mathematics. Interestingly, that is not the case. De Franco [1991] compared the problem solving performance of eight mathematicians who had achieved national or international recognition in the mathematics community with that of eight published mathematicians (the number of publications ranged from 3 to 52) who had not achieved such clear recognition. He also had the mathematicians fill out questionnaires regarding their beliefs about and mathematics and their problem solving practices (e.g., whether they tried alternative ways to approach problems if their initial methods did not pan out). The conclusion [DeFranco 1991, p. 208]:

The responses to the questionnaire indicate that the beliefs about mathematics and problem solving held by subjects in group A [the prominent mathematicians] are dissimilar to those held by the subjects in group B. To the extent that beliefs impact problem solving performance, it would appear that the beliefs acquired by group A (group B) would positively (negatively) influence their performance on the problems.

\section{Implications for Assessment}

As highlighted in this chapter, a person's mathematical knowledge is far from the whole story. If you are interested in someone's mathematical proficiencythat is, what someone knows, can do, and is disposed to do mathematically then it is essential to consider all four aspects of mathematical proficiency discussed in this chapter. Knowledge plays a central role, as it must. But, an individual's ability to employ problem solving strategies, the individual's ability to make good use of what he or she knows, and his or her beliefs and dispositions, are also critically important. As DeFranco's research showed, this is not just the case for students as they learn mathematics. It is the case for professional mathematicians as well. 
With regard to assessments aimed at capturing students' mathematical proficiency, the key operative phrase was coined by Hugh Burkhardt some years ago: the nature of assessment (or testing) is critically important because "What You Test Is What You Get" (WYTIWYG).

The WYTIWYG principle operates both at the curriculum level and at the individual student level. Given the "high stakes" pressures of testing under the No Child Left Behind law [U.S. Congress 2001], teachers feel pressured to teach to the test - and if the test focuses on skills, other aspects of mathematical proficiency tend to be given short shrift. (This is known as curriculum deformation; see Chapter 1 for an example.) Similarly, students take tests as models of what they are to know. Thus, assessment shapes what students attend to, and what they learn.

As noted in Chapter 1, skills are easy to test for, and tests of skills are easy to defend legally (they have the "right" psychometric properties). However, there are still significant issues with regard to problem solving and conceptual understanding. In this chapter, the comparison of students' SAT-9 and Balanced Assessment scores in my discussion of the knowledge base makes that point dramatically. Aspects of strategy, metacognition, and beliefs are much more subtle and difficult to assess. Yet, doing so is essential. Some of the chapters in the balance of this volume will describe assessments that attempt to capture some of the aspects of mathematical proficiency discussed here. To the degree that these assessments succeed in doing so, this represents real progress.

\section{References}

[Carpenter et al. 1983] T. P. Carpenter, M. M. Lindquist, W. Matthews, and E. A. Silver, "Results of the third NAEP mathematics assessment: Secondary school", Mathematics Teacher 76:9 (1983), 652-659.

[CSBE 1997] California State Board of Education, Mathematics: Academic content standards for kindergarten through grade twelve, Sacramento, 1997. Available at http://www.cde.ca.gov/be/st/ss/mthmain.asp. Retrieved 1 Nov 2005.

[DeFranco 1991] T. DeFranco, "A perspective on mathematical problem-solving expertise based on the performances of male Ph.D. mathematicians", pp. 195-213 in Research in collegiate mathematics education, II, edited by J. Kaput et al., Washington, DC: Conference Board of the Mathematical Sciences, 1991.

[Gardner 1985] H. Gardner, The mind's new science: A history of the cognitive revolution, New York: Basic Books, 1985.

[Lampert 1990] M. Lampert, "When the problem is not the question and the solution is not the answer", American Educational Research Journal 27 (1990), 29-63.

[Lester 1994] F. Lester, "Musings about mathematical problem solving research: 19701994”, Journal for Research in Mathematics Education 25:6 (1994), 660-675. 
[NCTM 1989] National Council of Teachers of Mathematics, Curriculum and evaluation standards for school mathematics, Reston, VA: Author, 1989.

[NCTM 2000] National Council of Teachers of Mathematics, Principles and standards for school mathematics, Reston, VA: Author, 2000.

[NRC 2000] National Research Council (Committee on Developments in the Science of Learning, Commission on Behavioral and Social Sciences and Education), How people learn: Brain, mind, experience, and school, expanded ed., edited by J. D. Bransford et al., Washington, DC: National Academy Press, 2000.

[NRC 2001] National Research Council (Mathematics Learning Study: Center for Education, Division of Behavioral and Social Sciences and Education), Adding it up: Helping children learn mathematics, edited by J. Kilpatrick et al., Washington, DC: National Academy Press, 2001.

[Pólya 1945] G. Pólya, How to solve it: A new aspect of mathematical method, Princeton University Press, 1945.

[Pólya 1954] G. Pólya, Mathematics and plausible reasoning (2 vols.), Princeton University Press, 1954.

[Pólya 1981] G. Pólya, Mathematical discovery, combined ed., New York: Wiley, 1981.

[Ridgway et al. 2000] J. Ridgway, R. Crust, H. Burkhardt, S. Wilcox, L. Fisher, and D. Foster, MARS report on the 2000 tests, San Jose, CA: Mathematics Assessment Collaborative, 2000.

[Schoenfeld 1985] A. H. Schoenfeld, Mathematical problem solving, Orlando, FL: Academic Press, 1985.

[Schoenfeld 1987] A. H. Schoenfeld, "What's all the fuss about metacognition?", pp. 189-215 in Cognitive science and mathematics education, edited by A. H. Schoenfeld, Hillsdale, NJ: Erlbaum, 1987.

[Schoenfeld 1992] A. H. Schoenfeld, "Learning to think mathematically: Problem solving, metacognition, and sense-making in mathematics", pp. 334-370 in Handbook of research on mathematics teaching and learning, edited by D. Grouws, New York: Macmillan, 1992.

[Senk and Thompson 2003] S. L. Senk and D. R. Thompson (editors), Standards-based school mathematics curricula: What are they? What do students learn?, Mahwah, NJ: Erlbaum, 2003.

[U.S. Congress 2001] U.S. Congress, H. Res. 1, 107th Congress, 334 Cong. Rec. 9773, 2001. Available at http://frwebgate.access.gpo.gov. 
